\title{
Morphological and histochemical characterization of the secretory epithelium in the canine lacrimal gland
}

\author{
Tadashi Yasui, Kenya Miyata, Chie Nakatsuka, Azuma Tsukise, Hiroshi Gomi \\ Department of Veterinary Anatomy, College of Bioresource Sciences, Nihon University, Kanagawa, Japan
}

\begin{abstract}
In the present study, the expression of secretory components and vesicular transport proteins in the canine lacrimal gland was examined and morphometric analysis was performed. The secretory epithelium consists of two types of secretory cells with different morphological features. The secretory cells constituting acinar units (type A cells) exhibited higher levels of glycoconjugates, including $\beta$-GlcNAc, than the other cell type constituting tubular units (type T cells). Immunoblot analysis revealed that antimicrobial proteins, such as lysozyme, lactoferrin and lactoperoxidase, Rab proteins (Rab3d, Rab27a and Rab27b) and soluble $N$-ethylmaleimide-sensitive fusion protein attachment protein receptor (SNARE) proteins (VAMP2, VAMP4, VAMP8, syntaxin-1, syntaxin-4 and syntaxin-6), were expressed at various levels. We immunohistochemically demonstrated that the expression patterns of lysozyme, lactoferrin, Rab27a, Rab27b, VAMP4, VAMP8 and syntaxin-6 differed depending on the secretory cell type. Additionally, in type T cells, VAMP4 was confined to a subpopulation of secretory granules, while VAMP8 was detected in almost all of them. The present study displayed the morphological and histochemical characteristics of the secretory epithelium in the canine lacrimal gland. These findings will help elucidate the species-specific properties of this gland.
\end{abstract}

Key words: dog; lacrimal gland; glycoconjugate; Rab protein; SNARE protein; electron microscopy.

Correspondence: Dr. Tadashi Yasui, Department of Veterinary Anatomy, College of Bioresource Sciences, Nihon University, 1866 Kameino, Fujisawa, Kanagawa 252-0880, Japan.

Tel. +81.466.843601 - Fax: +81.466.843601. E-mail: yasui.tadashi@nihon-u.ac.jp

Contributions: TY, designed the study, conducted the experiments and data analysis, and drafted the manuscript; $\mathrm{KM}$, CN, performed morphometric analysis, glycoconjugate cytochemistry and immunohistochemistry for VAMPs; AT, carried out the canine tissue sampling and contributed to the review of the manuscript; HG, carried out immunoblot analysis and contributed to the experimental design, data analysis and review of the manuscript. All the authors have read and approved the final version of the manuscript and agreed to be accountable for all aspects of the work.

Conflict of interest: The authors declare no conflicts of interest.

Ethics approval: All experiments were performed in accordance with the guidelines for the care and use of laboratory animals at the Institute of Experimental Animal Science, College of Bioresource Sciences, Nihon University (Approval Number AP14B056). 


\section{Introduction}

In humans, tear is composed of a complex mixture of various components, including numerous proteins, such as lysozyme, lactoferrin, secretory IgA, lipocalin and growth factors, and plays an essential role in maintaining the integrity of the ocular surface. ${ }^{1-4}$ The secretory cells of the lacrimal gland serve as a main source of tear proteins and fluid onto the ocular surface. These secretory proteins are secreted by a regulated or constitutive pathway. ${ }^{2} \mathrm{Rab}$ proteins are important regulators of intracellular vesicle trafficking. More than 60 Rab proteins have been identified in mammalian cells, and they exhibit ubiquitous or tissue-specific expression. ${ }^{5,6}$ According to previous studies, Rab3d, Rab27a and Rab27b are expressed in exocrine cells, such as acinar cells of the pancreas, ${ }^{7-9}$ parotid gland, ${ }^{10-12}$ and lacrimal gland. ${ }^{13-16}$ Soluble $N$-ethylmaleimide-sensitive fusion protein attachment protein receptor (SNARE) proteins mediate intracellular membrane fusion and can be functionally classified as v-SNARE and t-SNARE. ${ }^{17-19}$ Vesicleassociated membrane proteins (VAMPs), known as v-SNAREs, are associated with transport vesicles, while syntaxins, known as tSNAREs, are restrictedly distributed in the target membranes. These proteins have been shown to play an important role in neurotransmitter exocytosis of neuronal cells and to be involved in regulating exocytosis in several exocrine glands, including the lacrimal gland. ${ }^{20-25}$ However, most of the findings concerning Rab and SNARE proteins in exocrine glands are based on analyses of human and rodent tissues or cultured cells of exocrine gland origin. There are few reports on the expression of these proteins in the exocrine glands of other mammalian species, except for our recent studies. ${ }^{26,27}$ The lacrimal gland has been described as compound tubuloacinar or tubuloaveolar in structure, but the secretory unit distribution differs among mammalian species. The canine lacrimal gland is generally regarded as a seromucous gland. ${ }^{28-30}$ However, Kuhnel showed this gland to be purely a mucus gland. ${ }^{31}$ Therefore, the structural characteristics of this gland remain controversial due to the inconsistency in these findings. In dogs, the lacrimal gland and third eyelid gland are present as lacrimal apparatuses in the orbit, but the former is the main source gland of tears. Thus, the present study investigated the detailed ultrastructural features and distribution of glycoconjugates in the lacrimal gland of dogs. In addition, we attempted to elucidate the expression of antimicrobial, Rab and SNARE proteins by immunoblotting, immunohistochemistry and/or immunocytochemistry. The results obtained may be important not only for elucidating the morphological and functional characterization of the secretory epithelium in the canine lacrimal gland but also for understanding the differences with other mammalian species.

\section{Materials and Methods}

\section{Animals and tissue preparation}

Following euthanization under deep anesthesia, four male bea- gle dogs (aged 12, 14, 15 and 28 months; purchased from Kitayama Labes Co., Ltd., Nagano, Japan) were processed for sample preparation. For light microscopy, the tissue samples of the lacrimal gland located dorsolateral to the eyeball, the so-called main lacrimal gland, were fixed in Bouin's solution for $24 \mathrm{~h}$ at room temperature and then carefully dehydrated in a graded series of ethanol. These materials were embedded in paraffin wax and cut at a thickness of $5 \mu \mathrm{m}$. For general cytological observation, the tissue pieces were fixed in $2.5 \%$ glutaraldehyde (GA) in $0.1 \mathrm{M}$ phosphate buffer $\left(\mathrm{pH} \mathrm{7.4)}\right.$ for $2 \mathrm{~h}$ at $4^{\circ} \mathrm{C}$. They were postfixed in $2 \%$ osmium tetroxide solution for $2 \mathrm{~h}$ and embedded in Epon 812 in accordance with routine techniques. ${ }^{32}$ From these tissue blocks, ultrathin sections were cut on an ultramicrotome and mounted on copper grids. For cytochemical demonstration, the tissue specimens were fixed in $4 \%$ paraformaldehyde and $0.2 \%$ GA solution in $0.1 \mathrm{M}$ phosphate buffer ( $\mathrm{pH} 7.4$ ) for $2 \mathrm{hr}$ at $4^{\circ} \mathrm{C}$ and embedded in LR White resin. ${ }^{33}$ Ultrathin sections were cut as described above and placed on nylon or nickel grids. For immunoblotting, the lacrimal and parotid gland tissues were frozen on dry ice and stored at $-80^{\circ} \mathrm{C}$ until use.

\section{General morphology}

Deparaffinized sections were stained with hematoxylin-eosin (H-E) and Mallory-Azan for histological purposes. For electron microscopy, copper grid-mounted ultrathin sections were stained with $0.2 \%$ oolong tea extract (OTE) (Nisshin EM, Tokyo, Japan), $10 \%$ TI Blue (Nisshin EM) and lead citrate. The ultrathin sections prepared were examined under an electron microscope (JEM 1011; JEOL, Ltd., Tokyo, Japan). The size and number of secretory granules were analyzed by ImageJ 1.53 software.

\section{Glycoconjugate histochemistry and cytochemistry}

For light microscopy, the Alcian blue $\mathrm{pH}$ 2.5-periodic acid Schiff (AB-PAS) method was performed to demonstrate the presence of glycoconjugates. For lectin histochemical analysis, deparaffinized sections were treated with an Avidin/Biotin Blocking Kit (Abcam Plc., Cambridge, UK) and Dako REAL Peroxidase-Blocking solution (Agilent Technologies, Inc., Santa Clara, CA, USA). Then, the samples were incubated with different biotinylated lectins (J-Chemical, Inc., Tokyo, Japan) at concentrations of $10-20 \mu \mathrm{g} / \mathrm{ml}$ in $0.01 \mathrm{M}$ phosphate-buffered saline (PBS) $(\mathrm{pH}$ 7.4) overnight, followed by preincubation with $1 \%$ bovine serum albumin (BSA) (Sigma-Aldrich, St. Louis, MO, USA) in PBS. After PBS rinses, the sections were soaked in peroxidaselabeled streptavidin (Nichirei Co., Tokyo, Japan) for $30 \mathrm{~min}$ at room temperature and then visualized using the Diaminobenzidine (DAB) Peroxidase Substrate Kit (Vector Laboratories, Inc., Burlingame, CA, USA). In addition, these sections were counterstained with hematoxylin. The lectins used were concanavalin A (Con A), peanut agglutinin (PNA), wheat germ agglutinin (WGA) and Sambucus sieboldiana agglutinin (SSA). Their specific sugar residues are listed in Table 1. ${ }^{34,35}$ For glycoconjugate cytochemistry, nylon grid-mounted ultrathin sections were subjected to the periodic acid-thiocarbohydrazide-silver proteinate-physical development procedure (PA-TCH-SP-PD) for the demonstration of vic-

Table 1. The lectins used and their carbohydrate binding specificities.

\begin{tabular}{lcc} 
Lectins & Abbreviation & Carbohydrate binding specificity \\
Concanavalin A & Con A & $\alpha$-Man, $\alpha$-Glc \\
Peanut agglutinin & PNA & Galß1-3GalNAc \\
\hline Wheat germ agglutinin & WGA & $\beta-G l c N A c$ \\
Sambucus sieboldiana agglutinin & SSA & Sia $\alpha 2-6 \mathrm{Gal} / \mathrm{GalNAc}$ \\
\hline
\end{tabular}

Gal, galactose; GalNAc, N-acetyl-glactosamine; Glc, glucose; GlcNAc, N-acetyl-glucosamine; Man, mannose; Sia, sialic acid. 
inal diols of carbohydrates. ${ }^{36}$ The ultrathin sections on the nickel grids were pretreated with $1 \%$ BSA in PBS and then incubated with different biotinylated lectins (WGA, SSA) at concentrations of $5-10 \mu \mathrm{g} / \mathrm{ml}$ in PBS for $12 \mathrm{~h}$ at $4^{\circ} \mathrm{C}$. After PBS rinses, the sections were incubated with $15 \mathrm{~nm}$ colloidal gold-labeled streptavidin (BBI solutions, Crumlin, UK) at a dilution of 1:20 in PBS and then counterstained with OTE, TI Blue and lead citrate.

For specificity controls of the histochemical and cytochemical lectin procedures, sections were incubated with unconjugated lectins $(5-20 \mu \mathrm{g} / \mathrm{ml})$ instead of biotinylated lectins or with PBS without lectins.

\section{Immunoblotting}

Tissue sample preparation for sodium dodecyl sulfate-polyacrylamide gel electrophoresis (SDS-PAGE) and immunoblotting was performed as described previously. ${ }^{37}$ The parotid gland tissue was used as a control. Each protein extract, which was normalized to the total protein content $(25 \mu \mathrm{g})$, was subjected to SDS-PAGE and transferred to Immobilon-P or Immobilon-PSQ transferred membranes (Merck Millipore, Darmstadt, Germany). The primary antibodies used and their dilutions are listed in Table 2. For the analysis of antimicrobial proteins, primary antibodies against lysozyme, lacto- ferrin and lactoperoxidase were used. Primary antibodies against Rab3d, Rab27a, Rab27b, VAMP2, VAMP4, VAMP8, syntaxin-1, syntaxin- 4 and syntaxin- 6 were used to analyze Rab and SNARE proteins. Anti- $\alpha$-tubulin antibody was used as the loading control. The blocking treatment was performed by incubation with 5\% skim milk in Tris-buffered saline ( $\mathrm{pH} 7.4$ ) supplemented with $0.05 \%$ Tween 20 for $1 \mathrm{~h}$. The peroxidase-conjugated secondary antibodies (diluted 1:5000) used were as follows: goat anti-rabbit IgG, goat anti-mouse $\operatorname{IgG}$ and donkey anti-goat $\operatorname{IgG}$ (Jackson ImmunoResearch Laboratories, West Grove, PA, USA). Immunoblot analysis was performed as described previously. ${ }^{26,37}$

\section{Immunohistochemistry and immunocytochemistry}

For light microscopy, primary antibodies against lysozyme, lactoferrin, Rab3d, Rab27a, Rab27b, VAMP4, VAMP8, syntaxin-4 and syntaxin- 6 were used. Their dilutions are listed in Table 2. Deparaffinized sections were pretreated with microwave irradiation $(500 \mathrm{~W}, 6 \mathrm{~min})$ in $0.01 \mathrm{M}$ citrate buffer $(\mathrm{pH} 6.0)$ for antigen retrieval. The sections were immersed in Dako REAL PeroxidaseBlocking solution and blocked with $3 \%$ BSA in PBS. After incubation with primary antibodies overnight at $4{ }^{\circ} \mathrm{C}$, the sections were rinsed in PBS and then incubated with secondary antibodies using
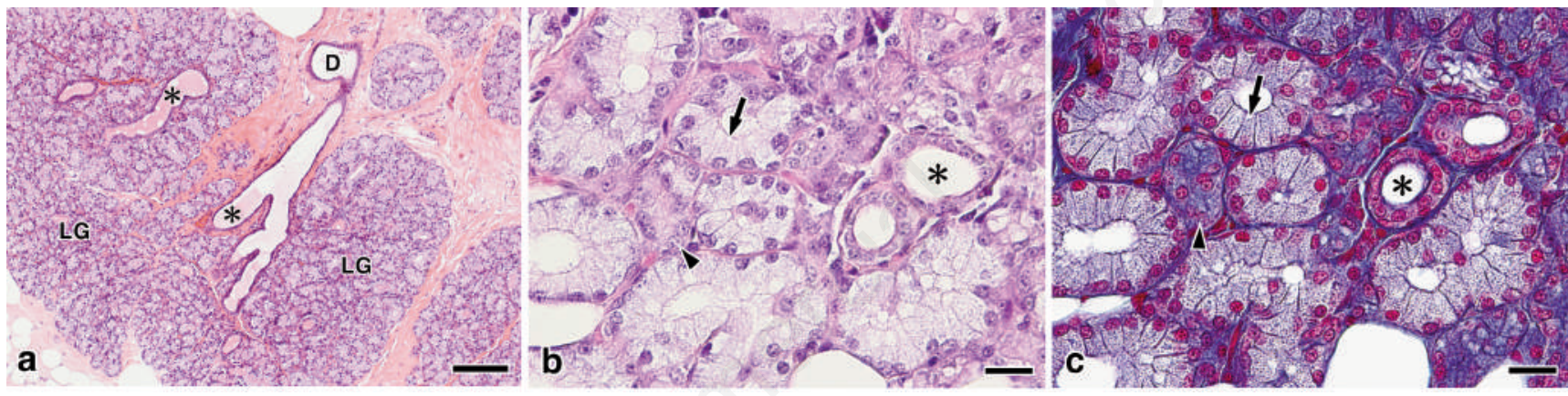

Figure 1. General histology of the canine lacrimal gland. a) The secretory portion forms a number of lobules; H\&E; scale bar: $150 \mu \mathrm{m}$. b) Higher magnification of the secretory epithelium stained with $\mathrm{H} \& \mathrm{E}$; scale bar: $20 \mu \mathrm{m}$. c) Higher magnification of the secretory epithelium stained with Mallory-Azan; scale bar: $20 \mu \mathrm{m}$. Arrows, type T cells; arrowheads, type A cells; asterisks, intralobular ducts; D, interlobular duct.

Table 2. Primary antibodies used for immunoblotting, immunohistochemistry and immunocytochemistry.

\begin{tabular}{|c|c|c|c|c|}
\hline Specificity & Host & Clonality & Dilution (usage) & Product* (catalog no.) \\
\hline Lysozyme & Rabbit & Polyclonal & 1:1000 (IB)/1:100 (LM) & Thermo (PA5-16668) \\
\hline Lactoferrin & Mouse & Monoclonal & 1:500 (IB, LM) & Abcam (ab10110) \\
\hline Lactoperoxidase & Goat & Polyclonal & $1: 7500$ (IB) & Abcam (ab82150) \\
\hline Rab3d & Rabbit & Polyclonal & 1:50 (IB)/1:100 (LM) & Proteintech (12320-1-AP) \\
\hline Rab27a & Rabbit & Polyclonal & 1:200 (IB)/1:100 (LM) & Proteintech (17817-1-AP) \\
\hline Rab27b & Rabbit & Polyclonal & 1:600 (IB)/1:100 (LM) & Proteintech (13412-1-AP) \\
\hline VAMP2 & Rabbit & Polyclonal & 1:500 (IB) & Thermo (OSS00035w) \\
\hline VAMP4 & Rabbit & Polyclonal & 1:200 (IB)/1:1000 (LM)1:500 (EM) & Abcam (ab80989) \\
\hline VAMP8 & Rabbit & Polyclonal & $1: 300$ (IB) & Aviva (ARP59536-P050) \\
\hline VAMP8 & Rabbit & Polyclonal & 1:400 (LM, EM) & Novus (NBP1-20232) \\
\hline Syntaxin 1 & Mouse & Monoclonal & 1:300 (IB) & Sigma-Aldrich (S0664) \\
\hline Syntaxin 4 & Rabbit & Polyclonal & 1:200 (IB, LM) & Atlas (HPA001330) \\
\hline Syntaxin 6 & Mouse & Monoclonal & 1:200 (IB)/1:100 (LM) & Abcam (ab56656) \\
\hline$\alpha$-Tubulin & Mouse & Monoclonal & 1:3000 (IB) & Sigma-Aldrich (T6199) \\
\hline
\end{tabular}

IB, immunoblotting; LM, light microscopic immunohistochemistry; EM, electron microscopic immunocytochemistry. *Products from Abcam Plc. (Cambrige, UK); Atlas Antibodies AB (Stockholm, Sweden); Aviva System Biology (San Diego, CA, USA); Novus Biologicals (Littleton, CO, USA); Proteintech Group, Inc. (Rosemont, IL, USA); Sigma-Aldrich, Inc. (St. Louis, MO, USA); Thermo Fisher Scientific (Rockford, IL, USA). 
the horseradish peroxidase (HRP)-labeled polymer technique (Envision+ Dual Link System-HRP; Agilent Technologies) for $1 \mathrm{~h}$ at room temperature. The immunoreaction was visualized using the DAB Peroxidase Substrate Kit and counterstained with hematoxylin. For electron microscopy, nickel grid-mounted ultrathin sections were incubated with primary antibodies against VAMP4 and VAMP8 overnight at $4{ }^{\circ} \mathrm{C}$, followed by pretreatment with $3 \%$ BSA in PBS. After PBS rinses, these ultrathin sections were incubated with biotinylated secondary antibody (dilution 1:500, donkey anti-rabbit IgG; Jackson ImmunoResearch Laboratories) and then with $15 \mathrm{~nm}$ colloidal gold-labeled streptavidin. Counterstaining was performed by the abovementioned procedure.

For negative controls for immunohistochemical and immunocytochemical procedures, the sections were incubated with a mixture of diluted primary antibodies that were pretreated with the respective absorbing antigens $(2-10 \mu \mathrm{g} / \mathrm{ml})$ or with normal rabbit or mouse IgGs ( $1 \mu \mathrm{g} / \mathrm{ml}$; Santa Cruz Biotechnology, Inc., Dallas, TX, USA) instead of the primary antibodies.

\section{Results}

\section{General morphological observation and morphometric analysis of secretory granules}

In the dog, the secretory portion of the lacrimal gland formed a number of lobules that were connected to the interlobular duct (Figure 1a). The lacrimal gland was tubuloacinar in configuration and found to consist of two types of secretory cells, which showed differential H-E and Mallory-Azan staining (Figure $1 \mathrm{~b}, \mathrm{c}$ ). Therefore, we classified the secretory cells constituting tubular units as type $\mathrm{T}$ cells and those constituting acinar units as type A cells. The type A cells were slightly more predominant (approximately 55\%) than in the type T cells (approximately 45\%). For general cytological observation, both cell types contained a welldeveloped Golgi apparatus and a large number of secretory granules within their cytoplasm, and the type T cells had a more promi-
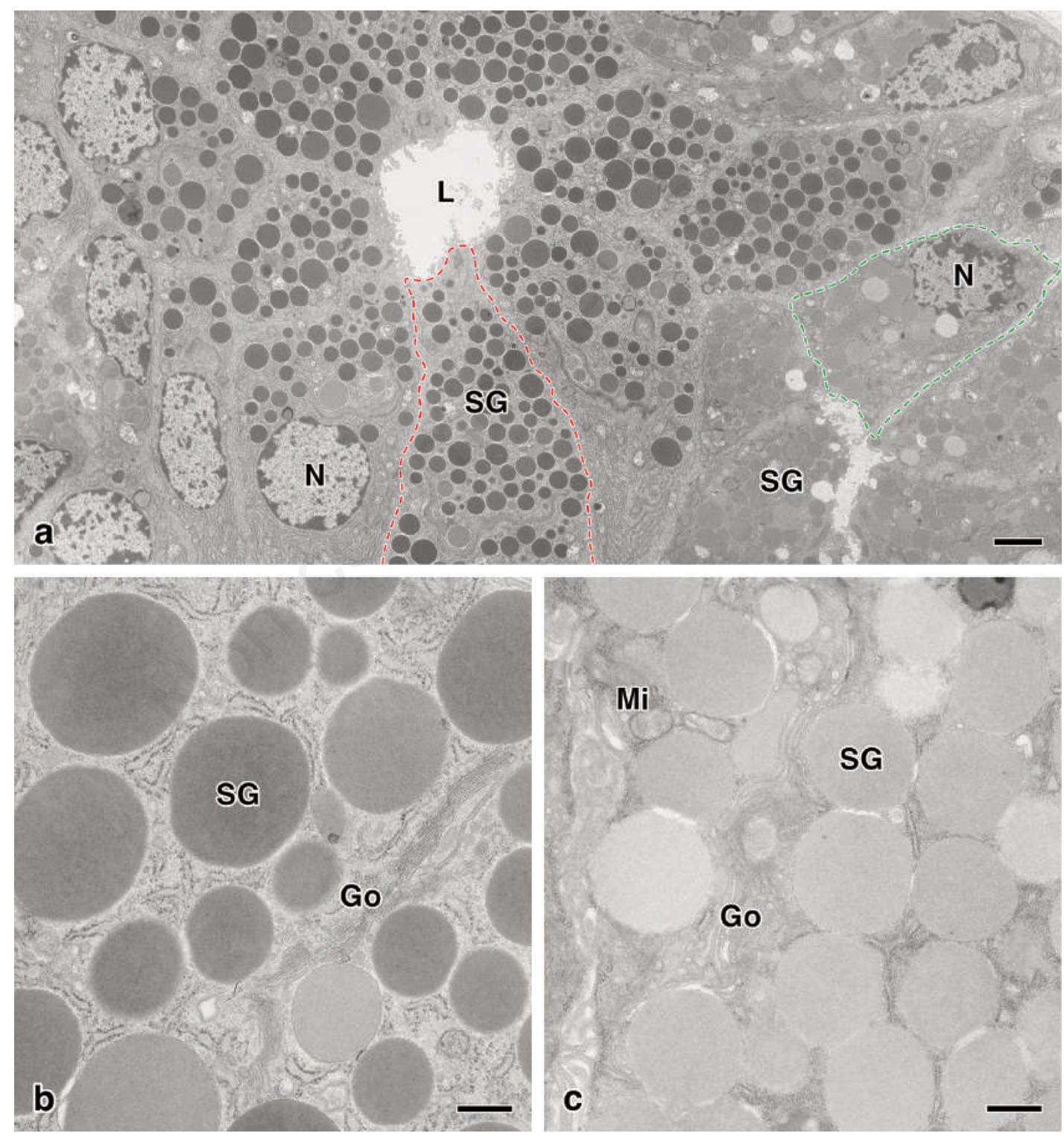

Figure 2. General ultrastructure of the lacrimal gland. a) The secretory portion consists of type T cells (red dashed line) and type A cells (green dashed line); scale bar: $2 \mu \mathrm{m}$. b) Higher magnification of type T cells; scale bar: $0.5 \mu \mathrm{m}$. c) Higher magnification of type A cells, scale bar: $0.5 \mu \mathrm{m}$. Go, Golgi apparatus, L, lumen, Mi, mitochondrion, N, nucleus, SG, secretory granule. 
nent rough endoplasmic reticulum than the type A cells (Figure 2 $\mathrm{a}-\mathrm{c})$. The secretory granules of the type $\mathrm{T}$ cells possessed relatively high electron density (Figure $2 \mathrm{a}, \mathrm{b}$ ), while those of the type A cells showed moderate electron density (Figure $2 \mathrm{a}, \mathrm{c}$ ). In addition, intercellular canaliculi were visualized between neighboring type A cells. For morphometric analysis, we examined the size and number of secretory granules in both cell types. The percentage of secretory granules $>0.8 \mu \mathrm{m}^{2}$ was higher in type T cells than in type A cells (Figure 3a). The mean secretory granular size in the former cell type was also larger than that in the latter cell type (mean \pm SEM, $0.738 \pm 0.01 \mu \mathrm{m}^{2}$ in type T cells $v s 0.585 \pm 0.008 \mu \mathrm{m}^{2}$ in type A cells). However, in both cell types, there was a variation in the mean of these sizes in each cell (Figure 3b). The mean granule density of the type A cells was higher than that of the type $\mathrm{T}$ cells $\left(0.61 \pm 0.03\right.$ number $/ \mu \mathrm{m}^{2}$ in type T cells $v s 0.82 \pm 0.04$ number $/ \mu \mathrm{m}^{2}$ in type A cells).

\section{Glycoconjugate histochemical and cytochemical obser- vation}

In the lacrimal glandular epithelium, the AB-PAS procedure gave rise to a weak positive reaction in the type T cells and a moderate or strong positive reaction in the type A cells (Figure 4a). For lectin histochemical methods, both cell types were found to exhibit positive reactions after treatment with Con A, PNA and SSA (Figure $4 \mathrm{~b}, \mathrm{~d}$ ). When incubated with WGA, however, a positive reaction was clearly confined to the type A cells (Figure 4c).

In ultrathin sections stained with the PA-TCH-SP-PD procedure, the secretory granules of the type T cells revealed a weak to moderate positive reaction, whereas a distinct positive reaction was observed in those of the type A cells (Figure $5 \mathrm{a}, \mathrm{b}$ ). Other prominent PA-TSH-SP-PD reactive structures were detected in the secretory cells at the surface coat of the plasma membrane and in cisternae of the Golgi apparatus. After the WGA-gold procedure, reactive particles were scarcely detectable in the type $T$ cells
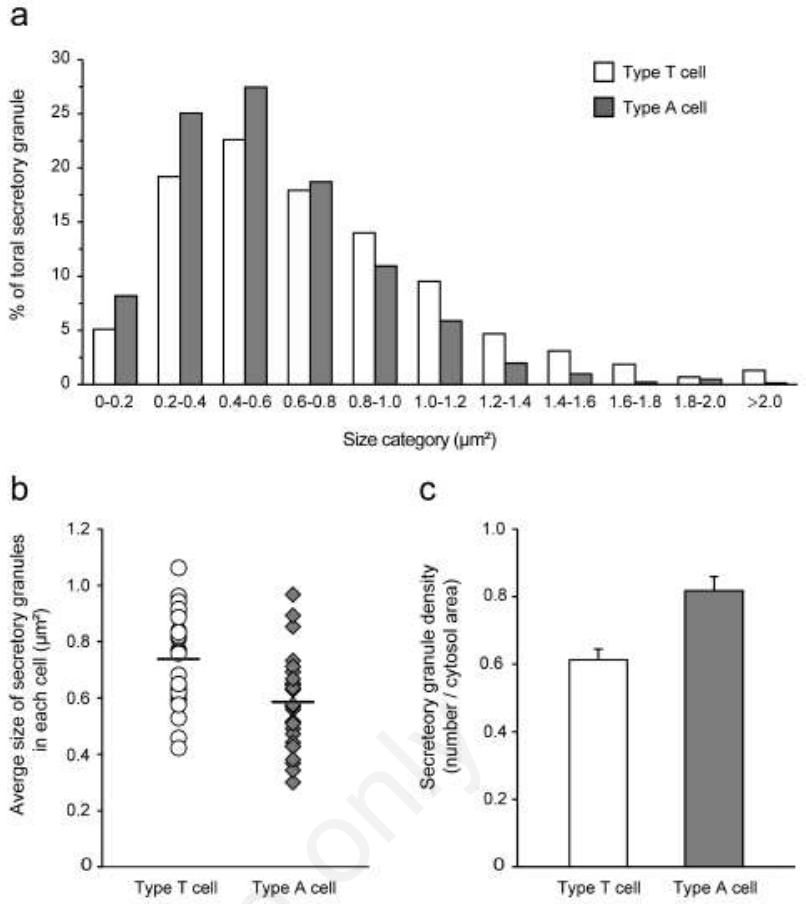

Figure 3. Morphometric analysis of secretory granules in the lacrimal gland. For each cell type, 10 randomly selected cells from three different animals were analyzed. a) Morphometric analysis of size distribution for secretory granules; the total number of secretory granules analyzed was 1606 from type $T$ cells and 1428 from type A cells. b) Average size of secretory granules in each cell. c) Average number of secretory granules per cytosol area $\left(\mu \mathrm{m}^{2}\right)$. The results are provided as the mean \pm SEM.
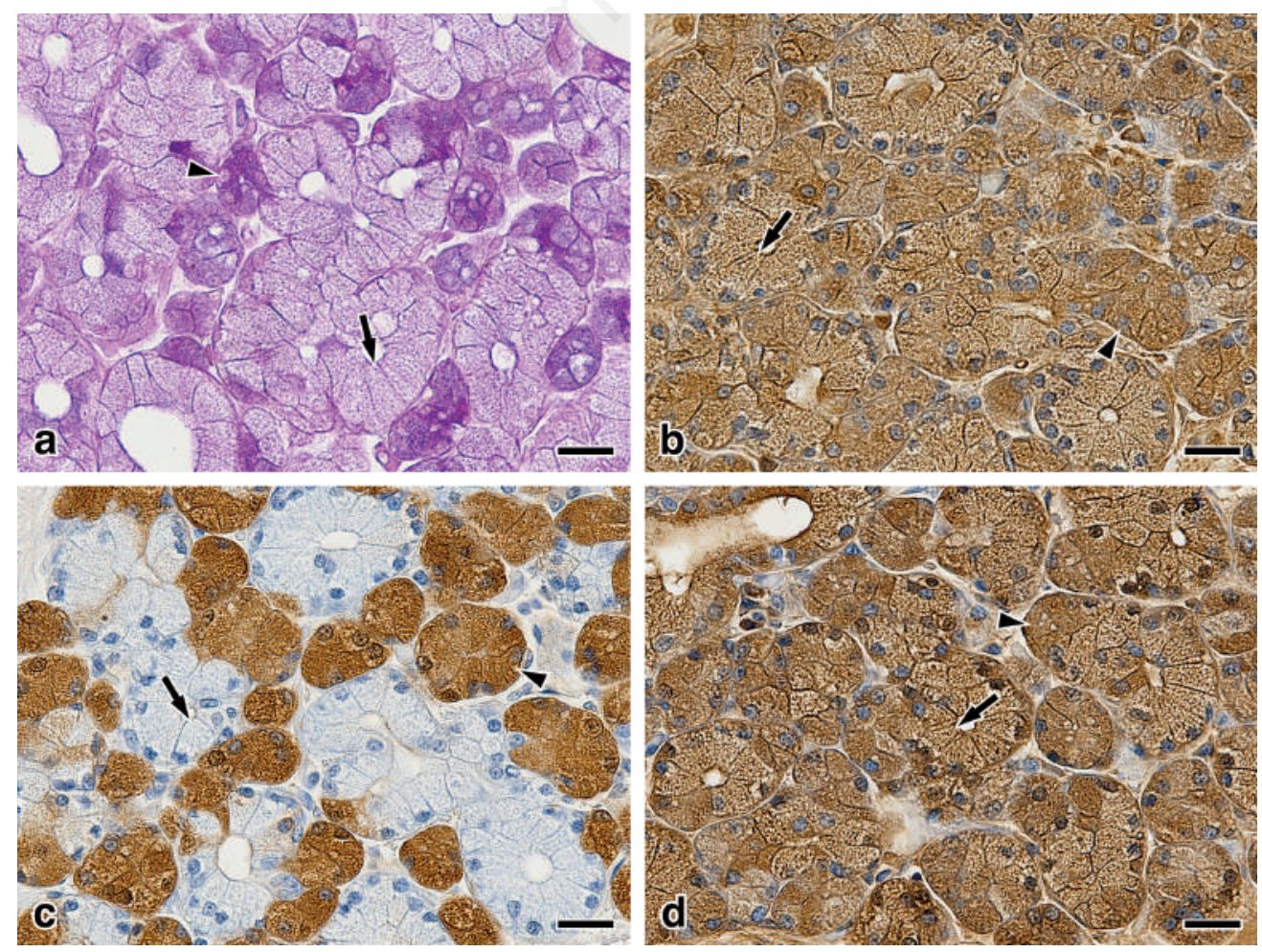

Figure 4. General glycoconjugate and lectin histochemical appearance of the lacrimal gland. a) AB-PAS. b) Con A. c) WGA. d) SSA. Arrows: type T cells, arrowheads: type A cells; scale bars: $20 \mu \mathrm{m}$. 
(Figure 5c). In contrast, the type A cells showed a distinct positive reaction in the secretory granules, Golgi apparatus and surface coat of the plasma membrane facing the lumen and intercellular canaliculus (Figure 5d). In the SSA-gold technique, both cell types displayed identical staining images in which gold particles were associated with the secretory granules, Golgi apparatus and surface coat of the plasma membrane (Figure 5 e,f)

In all of the control experiments for the lectin histochemical and cytochemical procedures, the positive reactions were greatly diminished or nearly abolished in the glandular structures of the lacrimal gland.
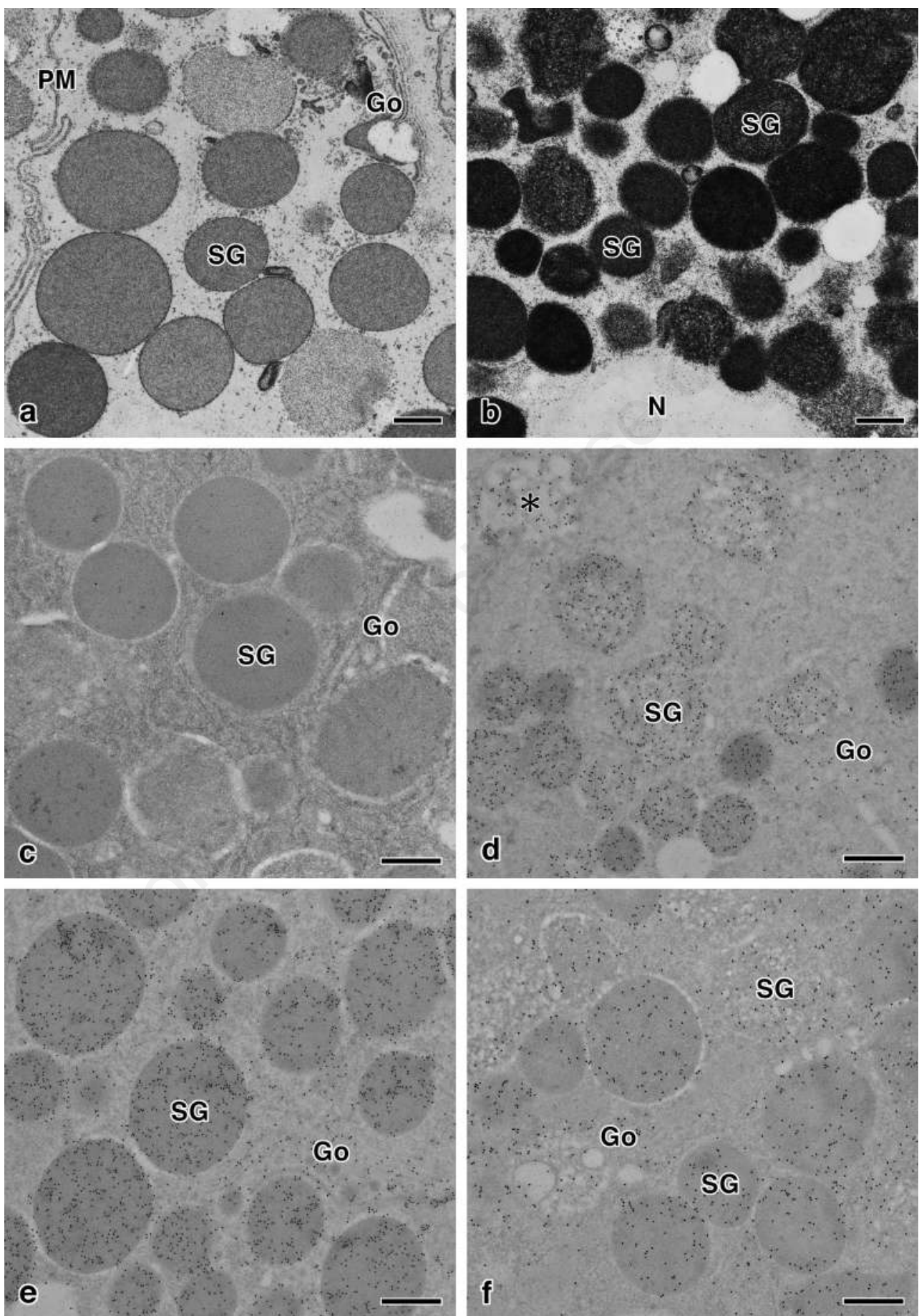

Figure 5. Glycoconjugate cytochemical staining in the lacrimal gland. a) Cytochemical PA-TCH-SP-PD staining of type T cells. b) Cytochemical PA-TCH-SP-PD staining of type A cells. c) WGA-gold staining of type T cells. d) WGA-gold staining of type A cells. e) SSA-gold staining of type T cells. f) SSA-gold staining of type A cells. Go: Golgi apparatus, N: nucleus, PM: plasma membrane, SG: secretory granule, asterisk: intercellular canaliculus; scale bars: $0.5 \mu \mathrm{m}$. 


\section{Expression of antimicrobial, Rab and SNARE proteins using immunoblotting}

The expression of antimicrobial, Rab and SNARE proteins was analyzed by immunoblotting (Figure 6). The expression pattern of antimicrobial proteins in the lacrimal gland was different from that in the parotid gland. In the lacrimal gland, lysozyme and lactoferrin were expressed, while the expression of lactoperoxidase could not be detected. With regard to Rab and SNARE proteins, their expression levels in the lacrimal gland were broadly similar to those in the parotid gland except for Rab3d, VAMP8 and Syntaxin-6. The signals for these proteins were more strongly detected in the lacrimal gland than in the parotid gland, especially for Rab3d and VAMP8.

\section{Immunohistochemical and immunocytochemical obser- vation}

For the immunohistochemical analysis of antimicrobial proteins, antibodies to lysozyme produced a weak positive reaction of the type $T$ cells, whereas a relatively strong positive reaction was detected in the type A cells (Figure 7a). In contrast, a positive reaction for lactoferrin was restricted to type $\mathrm{T}$ cells (Figure $7 \mathrm{~b}$ ). Regarding the immunohistochemical labeling for Rab and SNARE proteins, in both cell types, the secretory cells showed varying reaction intensities after treatment with antibodies to Rab3d (Figure 7c). Positive reactions for Rab27a and Rab27b were mainly observed in the type $\mathrm{T}$ cells (Figure $7 \mathrm{~d}$ ). A clear positive reaction for VAMP4 was also detected in the type T cells (Figure 7e), and the staining images of VAMP8 were similar to those of VAMP4 (Figure 7f). Incubation with antibodies against syntaxin-4 led to a staining pattern similar to that obtained with Rab3d (Figure 7g). Antibodies against syntaxin- 6 gave rise to a weak positive reaction in the type T cells (Figure 7h).

With regard to the immunocytochemical approach for VAMP4, a subpopulation of the secretory granules (approximately $23 \%$ of total secretory granules) in the type T cells showed a clear positive reaction in which reactive particles were associated with their membranes (Figure 8a). In addition, a few gold particles were occasionally detected in the Golgi apparatus of this cell type. Type A cells were almost all negative for antibodies to VAMP4. The immunocytochemical technique for VAMP8 demonstrated that reactive particles were observed in almost all the secretory granule membranes of the type $\mathrm{T}$ cells (Figure $8 \mathrm{~b}$ ). Specific labeling for VAMP8 was also found to be almost absent in type A cells, similar to VAMP4.

In the control experiments for the immunohistochemical and immunocytochemical procedures, the significant immunoreactivity of all the formerly reactive structures was strongly suppressed or abolished.

\section{Discussion}

The ocular surface is covered and protected by tear film possessing various functions, such as nutrition for the cornea, antimicrobial activity and lubrication. ${ }^{38}$ According to recent studies, the tear film is considered a bilayered structure, which consists of an aqueous mucin layer containing fluid, various proteins and secretory mucin, under a thin lipid layer. The lacrimal gland acts as a major contributor to the aqueous mucin layer. ${ }^{39-41}$ In dogs, the lacrimal gland and third eyelid gland are the two intraorbital glands, and it has been reported that approximately $70 \%$ of tear production originates from the former gland. ${ }^{42}$ The histological structures of the canine lacrimal gland (H-E and Mallory-Azan staining) were similar to those of seromucous glands such as salivary glands. However, the cytological and glycoconjugate histo- chemical observations of the secretory cells obtained differed from those of the salivary glandular cells. ${ }^{26,43,44}$ According to Martin et al., three types of secretory granules may be present in the acinar cells of canine lacrimal and third eyelid glands. ${ }^{30}$ The structural features of the granule type in tubular cells and the most common granule type in acinar cells correspond to our results except for the electron density of the latter. Electron-lucent secretory granules in the acinar cells, which are consistent with those shown by Kuhnel, ${ }^{31}$ could not be observed in this study. This discrepancy may be influenced by fixation or staining reagents. In addition, clusters of acinar cells containing lipid granules are present in the periphery of the third eyelid gland, but not in the lacrimal gland. ${ }^{30,45}$

The present study showed that both secretory cell types, classified as type T cells and type A cells, had different morphological and morphometrical features of the secretory granules.

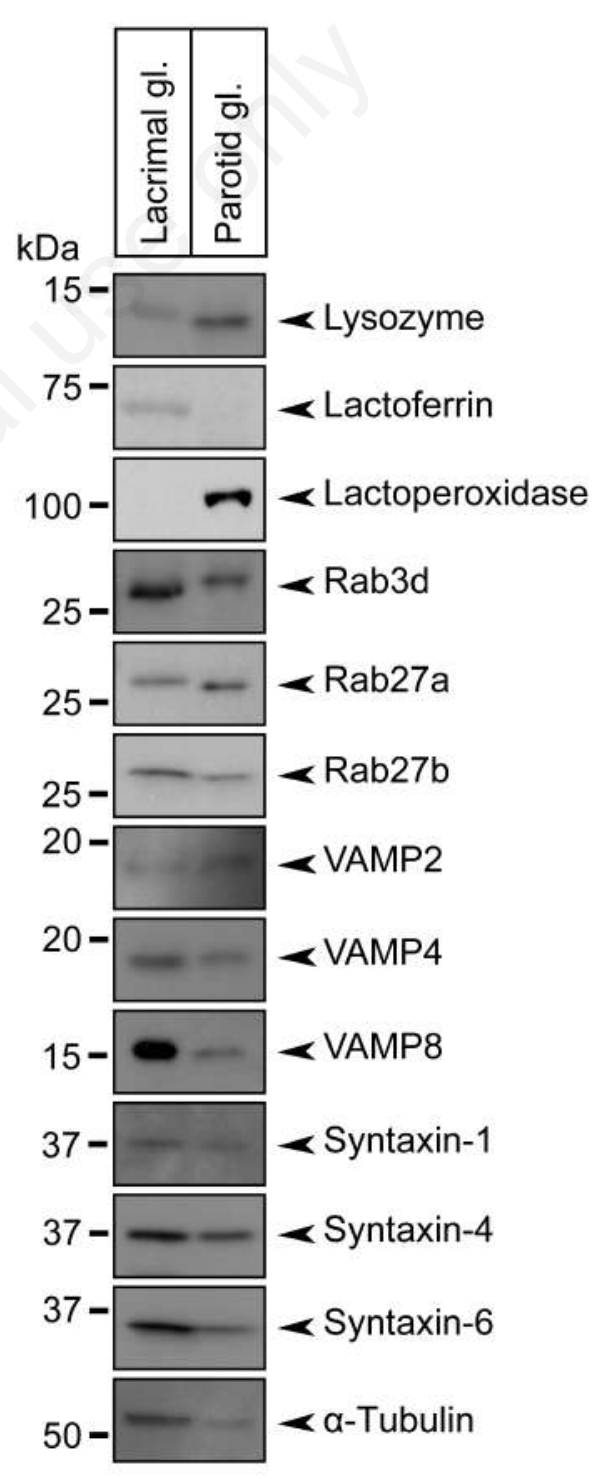

Figure 6. Expression of antimicrobial, Rab and SNARE proteins in the lacrimal gland. Equal amounts of protein extracts $(25 \mu \mathrm{g})$ from the lacrimal and parotid glands were subjected to SDSPAGE, followed by immunoblotting. The bottom panel shows the control $\alpha$-tubulin immunoblots. 

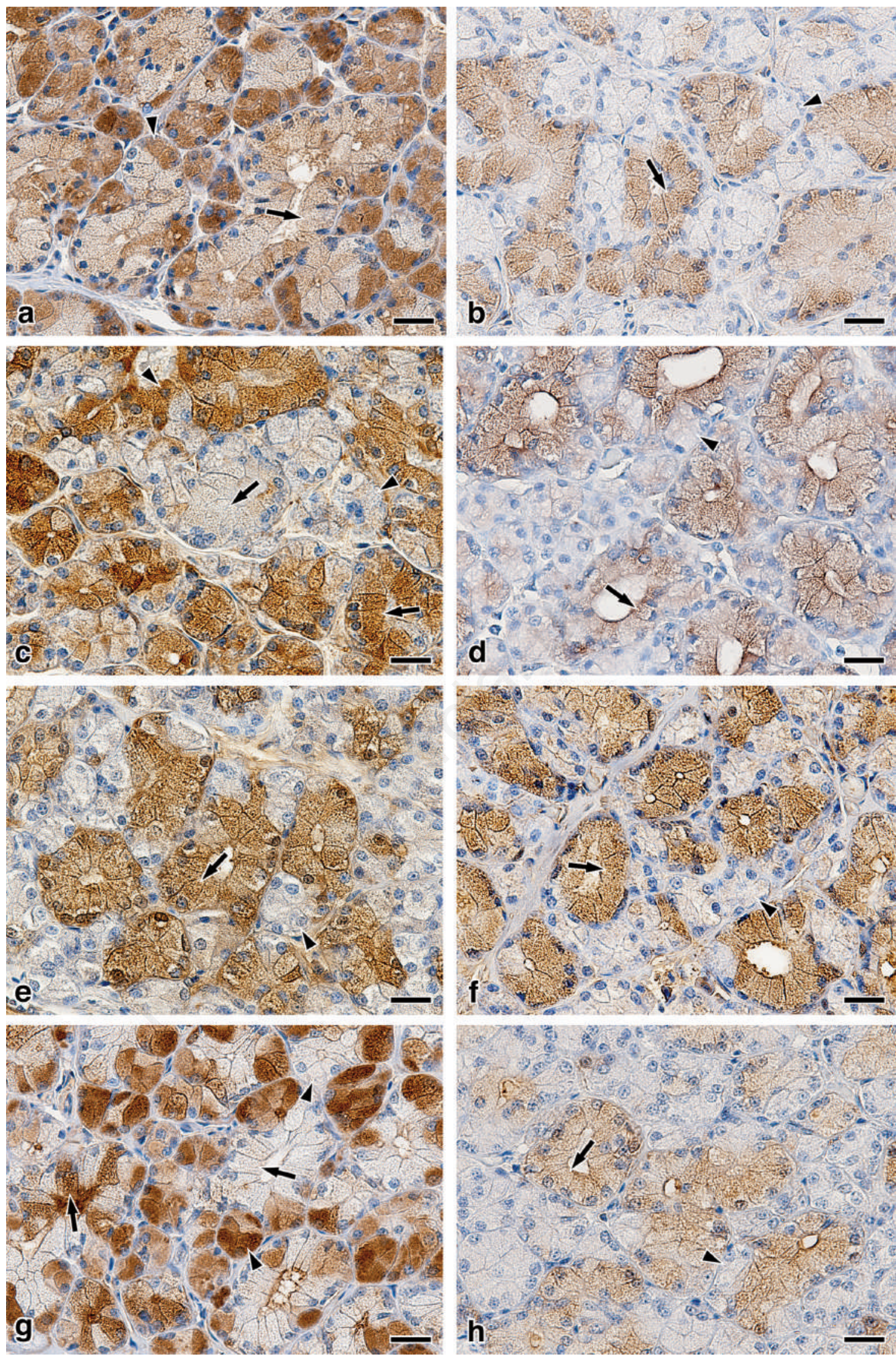

Figure 7. Immunohistochemical staining for the detection of antimicrobial, Rab and SNARE proteins in the lacrimal gland. a) Lysozyme. b) Lactoferrin. c) Rab3d. d) Rab27b. e) VAMP4. f) VAMP8. g) Syntaxin-4. h) Syntaxin-6. Arrows, type T cells; arrowheads, type A cells; scale bars: $20 \mu \mathrm{m}$. 
Furthermore, the secretory granules of the A cell type had a higher concentration of glycocojugates than those of the T cell type, as shown by the staining ability of the PA-TCH-SP-PD procedure. ${ }^{36}$ Although the presence of glycoconjugates with saccharide residues, such as $\alpha$-Man, Gal $\beta 1-3$ GalNAc and Sia $\alpha 2-$ $6 \mathrm{Gal} / \mathrm{GalNAc}$, was detected in both cell types by lectin histochemical and cytochemical procedures, the distribution of $\beta$-GlcNAc residues was confined to type A cells. Therefore, the glycoconjugate histochemical results obtained suggest that there is a qualitative difference in secretory products between both cell types. The ocular surface is constantly exposed to environmental pathogens, and thus human tear film includes antimicrobial proteins, such as lysozyme, lactoferrin, lipocalin and defensins, which are mainly secreted by the lacrimal gland. ${ }^{2,38,41,46,47}$ In this study, lysozyme and lactoferrin were expressed in the canine lacrimal gland, as shown using immunoblotting, whereas immunohistochemical analysis revealed that the localization of these proteins varied depending on the cell type. These findings are consistent with the abovementioned suggestion.

We demonstrated that Rab27a and Rab27b were predominantly expressed in type T cells of the canine lacrimal gland. Previous studies have provided evidence that Rab27a and Rab27b, which are localized on the secretory granule membranes of rat parotid and mouse pancreatic acinar cells, may regulate the secretion of digestive enzymes. ${ }^{8,9,48,49}$ Additionally, these isoforms seem to be involved in the release of secretory granules in rabbit primary cultured cells of the lacrimal gland. ${ }^{15,16}$ Functionally, Rab3d appears to play an important role during regulated exocytosis in exocrine secretion. ${ }^{7,11}$ However, the secretory granular size of parotid and pancreatic acinar cells in Rab3d knockout mice was significantly increased compared with that in wild-type mice, although the change in release kinetics in response to secretagogue stimulation was not detected, suggesting that Rab3d may be important for preventing homotypic fusion of secretory granules rather than for regulating exocytosis. ${ }^{50}$ Thus, the role of Rab3d in exocrine glands is not conclusive. In the present study, the immunoreactivity of Rab3d was inconsistent even in the same cell type, in addition to the variance in the mean size of the secretory granules in each cell.
Our results support the view that Rab3d participates in granule formation of exocrine glands.

This study also detected the expression of VAMP4, VAMP8, syntaxin- 4 and syntaxin- 6 in the canine lacrimal gland using immunoblotting. In addition, immunohistochemical analysis demonstrated that VAMP4, VAMP8 and syntaxin- 6 were predominantly expressed in type T cells. The expression of VAMP2 was observed in rabbit primary lacrimal acinar cells. ${ }^{13}$ However, in the present study, the expression level of VAMP2 was very weak, notwithstanding that the immunogenic peptides of the antiVAMP2 antibody used correspond exactly to the canine amino acid sequence. The weak signal for syntaxin-1 in immunoblot analysis is assumed to originate from the nerve fibers distributed in this gland, since this protein is known as an important t-SNARE in the release of a neurotransmitter from the synaptic vesicles of neurons. ${ }^{51}$ VAMP4, which colocalizes with syntaxin-6, is localized in the trans Golgi network (TGN) membranes, medial compartment of the Golgi apparatus, clathrin-coated and noncoated vesicles, endosomes and immature secretory granules in PC12 cells. Therefore, the interaction of VAMP4 with syntaxin- 6 may be involved in TGN-to-endosome transport. ${ }^{52}$ Additionally, in rat parotid acinar cells, it has also been suggested that VAMP4 and syntaxin- 6 are transported from immature secretory granules to early endosomes during the process of granule maturation..$^{53,54}$ The present study provided the first information, to our knowledge, on the localization of VAMP4 in exocrine gland tissues at the cytological level. The formation of the VAMP4/syntaxin-6 complex may have an important role in the maturation of secretory granules in the canine lacrimal gland based on the expression pattern of these proteins. Although VAMP8 was originally identified as an endosomal SNARE, ${ }^{55,56}$ this protein may be implicated in regulated granule secretion of platelets and mast cells. ${ }^{57,58}$ Previous studies using knockout mice have suggested that VAMP8 plays an important role in regulated exocytosis of pancreatic acinar cells, salivary glands and lacrimal glands by serving as a v-SNARE that may interact with syntaxin-4 and SANP-23.21,22 Additionally, there are alterations in the distribution and mRNA level of VAMP8 in the lacrimal gland with impaired secretory function, such as Sjögren's
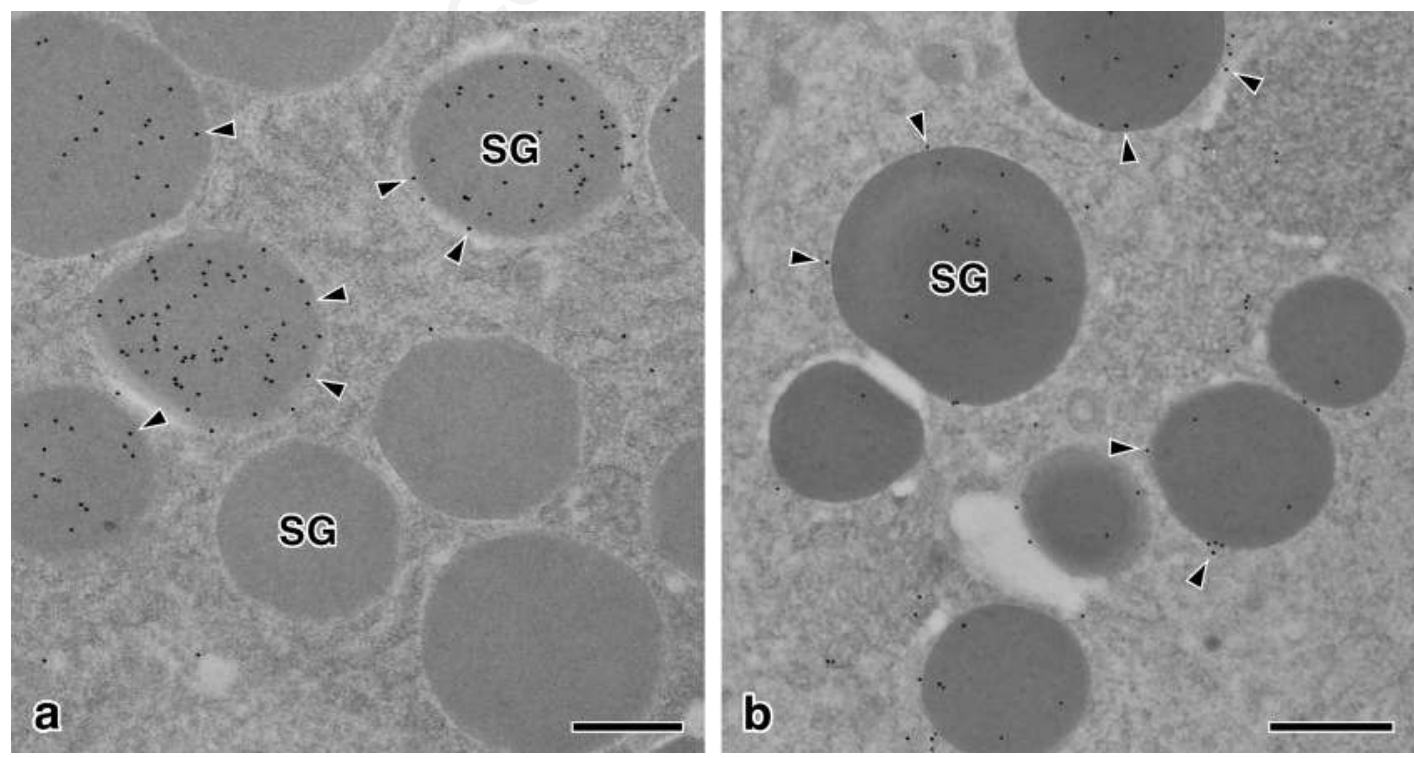

Figure 8. Immunocytochemical staining for the detection of VAMP4 and VAMP8 in the lacrimal gland. a) Immunogold labeling for VAMP4 of type T cells. b) Immunogold labeling for VAMP8 of type T cells. Arrowheads, reactive particles associated with secretory granule membranes; scale bars: $0.5 \mu \mathrm{m}$. 
syndrome, visual display terminal syndrome and chronic graft-versus-host disease. ${ }^{59,60}$ The localization of VAMP8 was observed in the membrane of the secretory granules in the type $\mathrm{T}$ cells of the canine lacrimal gland, identical to previous results indicating its presence in the zymogen granule membranes of pancreatic acini. ${ }^{21}$ VAMP8 may also be involved in regulated exocytosis in the canine lacrimal gland, even though the expression patterns of VAMP8 and syntaxin- 4 in the secretory epithelium were not necessarily consistent.

In conclusion, we demonstrated, for the first time in domesticated animals, that the secretory epithelium of the canine lacrimal gland displayed differences in the expression of secretory components and vesicular transport proteins between secretory cell types in addition to their morphological features. Although some have suggested that the ultrastructural variation of the seromucous and mucous cells in the human labial gland may reflect their different maturation stages, ${ }^{61}$ it is unclear whether the morphological and histochemical heterogeneity of the canine lacrimal gland is due to the different lineages or maturation stages of the secretory cells. Our findings indicate that this gland is composed of two types of secretory cells with different functional roles and secretory regulation, unlike humans. ${ }^{59,60,62}$ Such aspects may be related to the rate of tear evaporation and blinking, because a higher lipid level of tear film in dogs compared to humans seems to induce the prevention of tear evaporation, resulting in a slower blinking rate. ${ }^{63}$ Thus, the present study is indispensable for understanding the speciesspecific properties of the lacrimal gland and provides valuable information for elucidating the pathological mechanisms of diseases caused by secretory system disorders in dogs, such as keratoconjunctivitis sicca.

\section{References}

1. Fullard RJ, Snyder C. Protein levels in nonstimulated and stimulated tears of normal human subjects. Invest Ophthalmol Vis Sci 1990;31:1119-26.

2. Hodges RR, Dartt DA. Regulatory pathways in lacrimal gland epithelium. Int Rev Cytol 2003;231:129-96.

3. Sack RA, Conradi L, Krumholz D, Beaton A, Sathe S, Morris C. Membrane array characterization of 80 chemokines, cytokines, and growth factors in open- and closed-eye tears: angiogenin and other defense system constituents. Invest Ophthalmol Vis Sci 2005;46:1228-38.

4. Zhou L, Zhao SZ, Koh SK, Chen L, Vaz C, Tanavde V, et al. In-depth analysis of the human tear proteome. J Proteomics 2012;75:3877-85.

5. Grosshans BL, Ortiz D, Novick P. Rabs and their effectors: achieving specificity in membrane traffic. Proc Natl Acad Sci USA 2006; 103:11821-7.

6. Williams JA, Chen X, Sabbatini ME. Small G proteins as key regulators of pancreatic digestive enzyme secretion. Am J Physiol Endocrinol Metab 2009;296:E405-15.

7. Chen X, Edwards JAS, Logsdon CD, Ernst SA, Williams JA. Dominant negative Rab3D inhibits amylase release from mouse pancreatic acini. J Biol Chem 2002;20:18002-9.

8. Hou Y, Ernst SA, Stuenkel EL, Lentz SI, Williams JA. Rab27A is present in mouse pancreatic acinar cells and is required for digestive enzyme secretion. PloS One 2015;10:e0125596.

9. Hou Y, Ernst SA, Lentz SI, Williams JA. Genetic deletion of Rab27B in pancreatic acinar cells affects granules size and has inhibitory effects on amylase secretion. Biochem Biophys Res Commun 2016;471:610-5.

10. Ohnishi H, Ernst SA, Wys N, McNiven M, Williams JA. Rab3D localizes to zymogen granules in rat pancreatic acini and other exocrine glands. Am J Physiol 1996;271:G531-8.
11. Raffaniello RD, Lin J, Schwimmer R, Ojakian GK. Expression and localization of Rab3D in rat parotid gland. Biochim Biophys Acta 1999;1450:352-63.

12. Imai A, Yoshie S, Nashida T, Shimomura H, Fukuda M. The small GTPase Rab27B regulates amylase release from rat parotid acinar cells. J Cell Sci 2004;117:1945-53.

13. Wang Y, Jerdeva G, Yarber FA, da Costa SR, Xie J, Qian L, et al. Cytoplasmic dynein participates in apically targeted stimulated secretory traffic in primary rabbit lacrimal acinar epithelial cells. J Cell Sci 2003;116:2051-65.

14. Evans E, Zhang W, Jerdeva G, Chen CY, Chen X, HammAlvarez SF, et al. Direct interaction between Rab3D and the polymeric immunoglobulin receptor and trafficking through regulated secretory vesicles in lacrimal gland acinar cells. Am J Cell Physiol 2008;294:C662-74.

15. Chiang L, Ngo J, Schechter JE, Karvar S, Tolmachova T, Seabra MC, et al. Rab27b regulates exocytosis of secretory vesicles in acinar epithelial cells from the lacrimal gland. Am J Cell Physiol 2011;301:C507-21.

16. Meng Z, Edman MC, Hsueh PY, Chen CY, Klinngam W, Tolmachova T, et al. Imbalanced Rab3D versus Rab27 increases cathepsin S secretion from lacrimal acini in a mouse model of Sjögren's Syndrome. Am J Cell Physiol 2016;310:C942-54.

17. Söllner T, Whiteheart SW, Brunner M, Erdjument-Bromage H, Geromanos S, Tempst P, et al. SNAP receptors implicated in vesicle targeting and fusion. Nature 1993;362:318-24.

18. Rothman JE. Mechanisms of intracellular protein transport. Nature. 1994; 372:55-63.

19. Rothman JE, Warren G. Implications of the SNARE hypothesis for intracellular membrane topology and dynamics. Curr Biol 1994;4:220-33.

20. Imai A, Nashida T, Yoshie S, Shimomura H. Intracelular localization of SNARE proteins in rat parotid acinar cells: SNARE complexes on the apical plasma membrane. Arch Oral Biol 2003;48:597-604.

21. Wang CC, Ng CP, Lu L, Atlashkin V, Zhang W, Seet LF, et al. A role of VAMP8/endobrevin in regulated exocytosis of pancreatic acinar cells. Dev Cell 2004;7:359-71.

22. Wang CC, Shi H, Guo K, Ng CP, Li J, Gan BQ, et al. VAMP8/endobrevin as a general vesicular SNARE for regulated exocytosis of the exocrine system. Mol Biol Cell 2007; 18:1056-63.

23. Wu K, Jerdeva GV, da Costa SR, Sou E, Schechter JE, HammAlvarez SF. Molecular mechanisms of lacrimal acinar secretory vesicle exocytosis. Exp Eye Res 2006;83:84-96.

24. Weng N, Thomas DD, Groblewski GE. Pancreatic acinar cells express vesicle-associated membrane protein 2- and 8-specific populations of zymogen granules with distinct and overlapping roles in secretion. J Biol Chem 2007;282:9635-45.

25. Stoeckelhuber M, Scherer EQ, Janssen KP, Slotta-Huspenina J, Loeffelbein DJ, Rohleder NH, et al. The human submandibular gland: immunohistochemical analysis of SNAREs and cytoskeletal proteins. J Histochem Cytochem 2012;60:110-20.

26. Gomi H, Osawa H, Uno R, Yasui T, Hosaka M, Torii S, et al. Canine salivary glands: analysis of Rab and SNARE protein expression and SNARE complex formation with diverse tissue properties. J Histochem Cytochem 2017;65:637-53.

27. Yasui T, Gomi H, Kitahara T, Tsukise A. Ultrastructure and immunohistochemical characterization of proteins concerned with the secretory machinery in goat ceruminous glands. Eur J Histochem 2017;61:222-30.

28. Dellmann HD. Eye and ear. In: Dellmann HD, Brown EM, Editors. Textbook of veterinary histology. 2nd ed. Philadelphia: Lea and Febiger; 1981. p. 412-40.

29. Raskin RE. Eyes and adnexa. In: Raskin RE, Meyer DJ, 
Editors. Atlas of canine and feline cytology. Philadelphia: W.B. Saunders; 2001. p. 367-84.

30. Martin CL, Munnell J, Kaswan R. Normal ultrastructure and histochemical characteristics of canine lacrimal glands. Am J Vet Res 1988;49:1566-72.

31. Kuhnel W. [Vergleichende histologische, histochemische und electronenmikroskopische Untersuchungen an Tranedrusen 4 hund].[Article in German]. Z Zellforsch 1968;88:23-38.

32. Luft JH. Improvements in epoxy resin embedding methods. J Biophys Biochem Cytol 1961;9:409-14.

33. Newman GR, Jasani B, Williams ED. A simple post-embedding system for the rapid demonstration of tissue antigens under the electron microscope. Histochem J 1983;15:543-55.

34. Spicer SS, Schulte BA. Diversity of cell glycoconjugates shown histochemically: a perspective. J Histochem Cytochem 1992;40:1-38.

35. Danguy A. Perspectives in modern glycohistochemistry. Eur J Histochem 1995;39:5-14.

36. Yamada K. Histochemistry of carbohydrates as performed by physical development procedures. Histochem J 1993;25:95106.

37. Gomi H, Mori K, Itohara S, Izumi T. Rab27b is expressed in a wide range of exocytic cells and involved in the delivery of secretory granules near the plasma membrane. Mol Biol Cell 2007; 18:4377-86.

38. Ohashi Y, Dogru M, Tsubota K. Laboratory findings in tear fluid analysis. Clin Chim Acta 2006;369:17-28.

39. Gipson IK. Distribution of mucins at the ocular surface. Exp Eye Res 2004;78:379-88.

40. Paulsen F. Cell and molecular biology of human lacrimal gland and nasolacrimal duct mucins. Int Rev Cytol 2006;249:229-79.

41. Pflugfelder SC, Stern ME. Biological functions of tear film. Exp Eye Res 2020;197:108115.

42. Gelatt KN. Canine lacrimal gland and nasolacrimal disease. In: Gelatt KN, Editor. Veterinary ophthalmology. Philadelphia: Lea and Febiger; 1991. p. 276-89.

43. Habata I, Yasui T, Tsukise A. Histochemistry of sialoglycoconjugates in goat submandibular glands. Anat Histol Embryol 2011;40:187-95.

44. Habata I, Yasui T, Fujimori A, Meyer W, Tsukise A. Histochemical analyses of glycoconjugates and antimicrobial substances in goat labial glands. Acta Histochem 2012;114:454-62.

45. Sugiura Y, Soeta S, Ichihara T, Nishita M, Murakami M, Amasaki $\mathrm{H}$, et al. Immunohistolocalization and gene expression of the carbonic anhydrase isoenzyme (CA-II and CA-VI) in glands associated with the canine lacrimal apparatus. Anat Histol Embryol 2010;39:1-6.

46. Haynes RJ, Tighe PJ, Dua HS. Antimicrobial defensin peptides of human ocular surface. Br J Ophthalmol 1999;83:737-41.

47. Li N, Wang N, Zheng J, Liu XM, Lever OW, Erickson PM, et al. Characterization of human tear proteome using multiple proteomic analysis techniques. J Proteome Res 2005;4:2052-61.

48. Imai A, Nashida T, Yoshie S, Shimomura H, Fukuda M. Functional involvement of Noc2, a Rab27 effector, in rat parotid acinar cells. Arch Biochem Biophys 2006;455:127-35.

49. Imai A, Yoshie S, Nashida T, Fukuda M, Shimomura H.
Redistribution of small GTP-binding protein, Rab27B, in rat parotid acinar cells after stimulation with isoproterenol. Eur J Oral Sci 2009;117:224-30.

50. Riedel D, Antonin W, Fernandez-Chacon R, Alvarez de Toledo G, Jo T, Geppert M, et al. Rab3D is required for exocrine exocytosis but for maintenance of normally sized secretory granules. Mol Cell Biol 2002;22:6487-97.

51. Söllner T, Bennett MK, Whiteheart SW, Scheller RH, Rothman JE. A protein assembly-disassembly pathway in vitro that may correspond to sequential steps of synaptic vesicle docking, activation, and fusion. Cell 1993;75:409-18.

52. Steegmaier M, Klumperman J, Foletti DL, Yoo JS, Scheller RH. Vesicle-associated membrane protein 4 is implicated in trans-Golgi network vesicle trafficking. Mol Biol Cell 1999;10:1957-72.

53. Katsumata O, Fujita-Yoshigaki J, Hara-Yokoyama M, Yanagishita M, Furuyama S, Sugiya H. Syntaxin6 separates from GM1a-rich membrane microdomain during granule maturation. Biochem Biophys Res Commun 2007;357:1071-7.

54. Yokoyama M, Katsumata-Kato O, Fujita-Yoshigaki J. Syntaxin 6 is involved in the maintenance of secretory granules in parotid acinar cells. Int J Oral-Med Sci 2017;15:67-73.

55. Wong SH, Zhang T, Xu Y, Subramaniam VN, Griffiths G, Hong W. Endobrevin, a novel synaptobrevin/VAMP-like protein preferentially associated with the early endosome. Mol Biol Cell 1998;9:1549-63.

56. Advani RJ, Bae HR, Bock JB, Chao DS, Prekeris R, Yoo JS, et al. Seven novel mammalian SNARE proteins localize to distinct membrane compartments. J Biol Chem 1998;273:10317-24.

57. Paumet F, Le Mao J, Martin S, Galli T, David B, Blank U, et al. Soluble NSF attachment protein receptors (SNAREs) in RBL-2H3 mast cells: functional role of syntaxin 4 in exocytosis and identification of a vesicle-associated membrane protein 8-containing secretory compartment. J Immunol 2000;164: 5850-7.

58. Polgar J, Chung SH, Reed GL. Vesicle-associated membrane protein 3 (VAMP-3) and VAMP-8 are present in human platelets and are required for granule secretion. Blood 2002;100:1081-3.

59. Kamoi M, Ogawa Y, Nakamura S, Dogru M, Nagai T, Obata $\mathrm{H}$, et al. Accumulation of secretory vesicles in the lacrimal gland epithelia is related to non-Sjögren's type dry eye in visual display terminal users. PLoS One 2012;7:e43688.

60. Fukui M, Ogawa Y, Mukai S, Kamoi M, Asato T, Kawakami Y, et al. Reduced expression of VAMP8 in lacrimal gland affected by chronic graft-versus-host disease. J Ophthalmol 2017;2017:1639012.

61. Miyazaki T, Fujiki T, Inoue Y, Takano K. Immunoelectron microscopic identification of lysozyme-expressing cells in human labial salivary glands. Arch Histol Cytol 1998;61:199214.

62. Obata H. Anatomy and histopathology of the human lacrimal gland. Cornea 2006;25:S82-9.

63. Ofri R, Orgad K, Kass PH, Dikstein S. Canine meibometry: establishing baseline values for meibomian gland secretions in dogs. Vet J 2007;174:536-40.

Received for publication: 30 August 2021. Accepted for publication: 14 October 2021.

This work is licensed under a Creative Commons Attribution-NonCommercial 4.0 International License (CC BY-NC 4.0).

CCopyright: the Author(s), 2021

Licensee PAGEPress, Italy

European Journal of Histochemistry 2021; 65:3320

doi:10.4081/ejh.2021.3320

[European Journal of Histochemistry 2021; 65:3320]

open 2 Access 